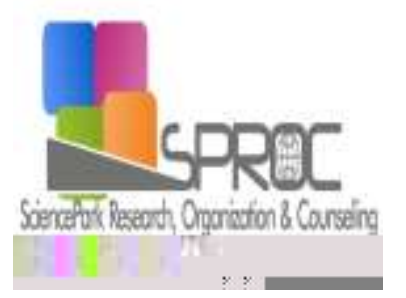

\section{New Trends and Issues Proceedings on Humanities and Social Sciences}

Volume 4, Issue 1 (2017) 472-480
'New Trends and lssues Proceedings on Humanities and Social Sciences

ISSN 2421-8030

www.prosoc.eu

Selected Papers of 9th World Conference on Educational Sciences (WCES-2017) 01-04 February 2017 Hotel Aston La Scala

Convention Center, Nice, France

\title{
PhD graduates and students: What professional pathways exist?
}

Aparicio Miriam Teresita ${ }^{a^{*}}$, College of Psychology Sciences. Av. Jose I. de la Roza 1516 oeste Rivadavia, Catholic University of Cuyo, 5400, San Juan, Argentina.

\section{Suggested Citation:}

Teresita, M. A. (2017). PhD Graduates and Students: What professional pathways exist?.

[Online]. 4(1), pp 472-480. Available from: $\underline{w w w . p r o s o c . e u}$

Selection and peer review under responsibility of Prof. Dr. Jesus Garcia Laborda, University of Alcala, Spain.

${ }^{\circ} 2017$ SciencePark Research, Organization \& Counseling. All rights reserved.

\begin{abstract}
This comparative study of education in Argentina and France has as its objective to analyze both the current position of PhDs and $\mathrm{PhD}$ students and the expectations for their professional futures in the humanities under the current structural framework. This framework does not always allow them to be absorbed in the scientific and/or business systems, especially in developed countries where the number of PhDs produces a "plafond" effect. Our theoretical framework focuses on two issues: a) professionalization and b) identity. Our methodology is qualitative (hierarchical evocation and interviews). The results bring to light aspects hidden by the media and reveal the "reasons" both groups of PhDs give for their professional positions and expectations as well as impressions of values privileged and/or "imposed" by the macro national level. Similarities and differences show high institutional, disciplinary and national homogeneity. These are interpreted in light of a social-systemic paradigm sui generis (Aparicio, $2015 \mathrm{a}, \mathrm{b})$.
\end{abstract}

Keywords: PhDs; professional pathways; professional mobility; identity; professionalization.

* ADDRESS FOR CORRESPONDENCE: Aparicio Miriam Teresita, College of Medical Sciences. Av. Jose I. de la Roza 1516 oeste Rivadavia, Catholic University of Cuyo, 5400, San Juan, Argentina. : maparici@atlink.com.ar / Tel.: +446 2 522-2021 


\section{Introduction}

This comparative research, which links Higher Education and the Workplace, has as its objective to analyze factors that influence the professional development and mobility of PhDs in structural and corporate contexts that do not always offer conditions favorable for professional development or mobility and within a scientific system that cannot always absorb a significant percentage of these PhDs. This could result in serious difficulties for workplace insertion and promotion, with expected diversions on two levels: a) individual (at the level of personal achievement, expectations, marked by a notable sense of pessimism in Europe - as recently released value surveys show -, high degrees of ambivalent resignation/conformity, frustration, weakening commitment and increased burnout (when identity strategies to "survive" with resilience to demands are not sufficient). b) At the institutional level, our studies show, for different levels of the education system, though particularly at the undergraduate and graduate levels, the need for the professionalization and renovation of cultural standards that, traditionally, regulated institutions. In effect, many - despite the importance given to PhDs in terms of innovation - continue to be regulated by "inherited norms" without generating new programs more in line with new demands (the quasi absence of the criteria of belonging or institutional response to contextual needs as a criteria for institutional quality) (Aparicio, 2005; 2007a; 2009c, 2015b, 2015d and e; 2016). Numerous studies carried out over the course of 30 years are cited in these works).

This study represents a continuation of other

studies on the pathways of university graduates: undergraduates from different programs and universities (National University of Cuyo, UNCuyo, and the National Technical University, UTN, in Argentina; graduate students (masters and PhD students) from Argentina and abroad; individuals delayed in the university system and individuals that drop out, in relation to conditioning factors. These are the only comparative studies of this kind (19802014) (Aparicio, 2003, 2008, 2009a, 2009b).

Nevertheless, our study offers the following original aspects: a) it is a comparative study in a field that does not have an abundance of these studies: education; b) it addresses an educational level that is largely unstudied - the PhD level - and the variables associated with levels of achievement in theory; c) it analyzes the Status and Professional Mobility related to Professionalization and Identity using qualitative techniques. This is of special interest as "education/training" has historically been considered a "semi-profession" (Etzioni, 1969) and its "proletariat" agents (Ozga \& Lawn, 1981). Currently, many believe in that which is sustained by the media, a new "devaluation" of the teacher as such and of the teaching career. d) The interpretation of data has been carried out using the author's systemic perspective sui generis that involves three levels in interaction: the individual, the organizations and the macro context. This perspective has been called

(Aparicio, 2015b).

The issue's relevance is marked by different factors: a) the uncertain future of PhDs is beginning to occupy international agendas, and also our country's agenda. Scientific organizations are significantly increasing their scholarship quotas looking to obtain more PhDs and Argentine universities are making enormous efforts to increase their graduate offerings, though this is not always done with consideration of studies of demands and later affects PhD pathways. Despite this reality, Argentina's situation as regards PhDs in Human and Social Sciences is particular as the country still has a restricted number of degree programs for political reasons. In effect, the "plafond" effect (that is, saturation of offerings) that has been observed in developed countries may not exist in Argentina, as the doctorate still remains a channel for professional mobility and development. This leads us to one of our hypotheses. b) We are unaware of international studies carried out with the methodology we select nor of personalized work with each PhD that uncovers the value given to having a doctorate for the professional pathway and the underlying "reasons" associated with achievement (objective and subjective). Studies that have been carried out have utilized secondary data, ignoring the relationships that these pathways have with institutions and other sociocultural and psychosocial factors from follow-up studies. c) Finally, we point out that the present research is part of a research program on the in Argentina which, having been started in 1995, continues to focus on say, it does not take into account the

. That is to that are at the base 
of these statistics (to take one case, the graduation rate). Faced with this reality, we take a holistic and integrated perspective of and products, of "mechanisms" that anticipate achievement at the psycho-individual level, while at the same time passing through the meso-institutional/organizational level (university/workplace).

\section{Theoretical Framework}

Two theoretical axes underlie our analysis: a) the issue of professionalization or lack of professionalization and their implications at the level of identity and identity strategies being used; $b$ ) Other core analyses that relate different theories: Expectancy-Value (Feather \& Davenport, 1981); the so-called "Investment-Consumption" theories (Becker, 1964; Mingat \& Rassera, 1981); the Line Waiting theory (García Rodríguez, 1993); that proposed by Boudon, Bulle and Charkaoui, 2001; and the Theory of Wellbeing and related theories (Salanova et al., 2005), among others. We add to these theories the author's theory, which will not be discussed in detail in this article. This theory presents three interacting levels that provide an understanding of the "deeper sense", both of individual, institutional and macro national behavior, from a singular dialectic (Aparicio $2015 \mathrm{a}$ and b).

Due to questions of brevity, we are unable to describe each theory in detail. We will only mention, as regards the first theory cited (Expectancy-Value), that prioritizing values such as stability opposite prestige means that when faced with adverse circumstances from an economic point of view and relatively low salaries, those who have chosen "education" as a profession do not feel as though they have failed: "no expectations mean no desperation" (Levy-Leboyer, 1971). As regards the Investment Consumption and Line Waiting theories (with influences on others such as the theory of Wellbeing), education can be seen as an "investment", that is, as that which will allow access to positions of prestige and/or power in society (Heintz, 1970) or that will allow for a certain stability and wellbeing, associated with the practice of a vocational calling. Both axes are related to different biographical, sociocultural and institutional profiles: those who choose prestige generally tend to come from families that are well off both economically and socially. As they have high expectations for economic growth in the future, they enter degree programs that offer high levels of difficulty. On the contrary, those who opt for the dimension of "consumption" tend to come from less favored social strata and enter institutions that are less demanding (rigor, time, competencies, etc.) where, in general, entrance is easier and the future is less promising economically speaking. Nevertheless, this does not compromise a sense of wellbeing (Aparicio, 2005, 2008, 2009 c). See "founding fathers" and specific bibliography. Also, 2009 a and b).

With respect to

and its relation to professional pathways and identity crises frequently observed as impacting health and even institutional/organizational efficacy -, we must remember that this issue has been present on the agendas of northern countries since the 1980s, whereas it emerges much later in less developed countries. On the one hand, the effects of the "massification" of higher education (Bourdoncle, 1993; Gelin, Rayou \& Ria, 2007) have demonstrated the need to , as well as implementing new modalities. On the other hand - and what strictly concerns this research study - the conditions needed to perform in today's workplace have changed and professional insertion, in addition to permanence and promotion, have become issues that require urgent and innovative institutional responses in a globalized world that is increasingly changing and competitive at the professional level. This includes education in competencies that surpass disciplinary competencies. Our research, which covers more than 20 years at different institutions, demonstrates that excellence at University is no longer enough to ensure expected positioning in the corporate sector. In complementary studies, other competencies have become predicative of professional achievement, particularly those which the author classifies as "social" together with collective competencies (Argirys \& Shon, 1993).

Briefly speaking, the accelerated pace of change requires innovative transformations of educational institutions and an affirmation of new competencies that could have an impact on and renew institutional and professional identity - an identity which today is often weakened by a lack of recognition and the devaluation of the image of some professionals, together with the incongruence between certain educational and workplace policies (Ozga \& Lawn, 1981; Tardiff \& Lessard, 1999). 
Generally, from a reading of specific literature from the sociological-educational field, we can say that tension exists between the workplace and education programs as well as between what is expected when choosing an academic program and what is experienced in the professional realm. In addition, the of institutional/organization orientations to respond to changes in the professional world is different from the under-prescription of concrete means to access them (Goffman, 1963). Within this framework, the links between personal pathways, educational pathways and professional pathways have become a focus of concern in the field and particularly for programs in human and social sciences.

In Argentina, this issue has not been well developed. Nevertheless, in our own research with university graduates (Aparicio 1995-2014), a gap clearly emerges between disciplinary knowledge and competencies demanded by the context, and between the "ideal" situation imagined when starting a university program and the "real" professional situation experienced by graduates. Identity crises in an unstable world emerge from social representations of what professional practice implies (Dubar, 1991; 1992). In terms of what concerns us here, this issue is key in order to truly understand the problem of

(though they do not always do so) the official workplace or prescriptive situation and the subjective situation faced daily.

\section{Objectives}

\subsection{General}

At the theoretical level, we seek to: a) identify sociocultural, pedagogical, institutional, psychosocial and organizational factors/dimensions that impact $\mathrm{PhD}$ pathways, based on the shared representations prioritized (the words of the actors themselves, the frequency with which they are used and the importance given them). b) understand the "deeper motivations" that underlie relative achievement, observed in terms of education received, professionalization and identity; professional mobility and professional satisfaction in relation to the expectations that PhDs have in different disciplinary and institutional contexts; c) comprehend which competencies are taught by the education system and which are "largely absent" despite being required by the workplace. At the level of application, transferring these aspects to decision makers could result in the implementation of corrective and preventative measures, and as such help to avoid frustration at the individual level and improve institutional quality.

\subsection{Specific}

a) To understand and compare (descriptive level) the sociological, psychosocial and institutional problems as "contextualized" in order to avoid acritical extrapolations, considering that professional insertion and promotion is today an international issue (generalized conditions of unease when entering the professional workplace and when practicing the profession within organizations). b) To comprehend the representations that both groups of PhDs have of the value of their diploma in the workplace and of their doctoral education in terms of acquiring and/or consolidating competencies, as well as their vision of future professional opportunities. c) To observe the relationship between different types of education and organizations and levels of achievement for PhDs in Education in both groups (French and Argentine).

\section{Hypotheses and Central Questions}

\subsection{Hypotheses}

a) Completing doctoral studies will lead to better workplace insertion in our context. b) "Plafond" effects and the devaluation of diplomas will be observed to a greater degree in the French context due to its long history of doctoral programs; c) The actors' shared representations and the different valuation of factors such as stability opposite prestige or power will be associated with feelings of achievement and wellbeing of those who choose the academic option of "education". 


\subsection{Central questions}

In what professional structures are PhDs in Education located? Which aspects define their real insertion in terms of objective achievement, satisfaction, hierarchical positioning and, if applicable, professional mobility? What expectations do they maintain in relation to their level of studies reached? What representations do they have as regards education as a vehicle for progress? Which values are prioritized by those who choose "education" knowing that conditions for workplace insertion are limited in general, to state positions, both in the academic and scientific systems? Do they prioritize stability and achievement over the economic benefits that could be associated with obtaining a doctorate? (we remember " my son the doctor ", a strong cultural image in Argentina) How do they perceive their professional future? Do they demand professionalization? What is dominant in each group: fatalism or hope? Do they share specific "identities" and "interests"? What are the most important differences observed? All of these elements are key to the configuration of professional identity in different groups. This comparative study allowed us to better understand these identities and associated professionalization needs.

\section{Method}

The methodology utilized was, fundamentally, qualitative.

\subsection{Population}

Our study sample was made up of doctoral students and PhDs from UNCuyo and doctoral students and $\mathrm{PhDs}$ from Cnam (Paris) from different degree programs in the human and social sciences (Education, Management/Administration, Psychology and Sociology), universities that serve similar populations. In this paper, we focus only on the population of students of Education (in France, the program is called Adult Education). We include those who entered the respective programs starting in 2005, some of whom reached graduation (More details of the sample can be found in Aparicio, 2009d (Rapport a la Marie de Paris, Award) and Aparicio and Cros (2015c). Here you will find, for all the degree programs studied, a detailed analysis of 6 of the Nodes analyzed, with information provided by the actors themselves.

\subsection{Techniques}

Interviews with all actors were carried out in order to understand in depth and their central motivations for choosing a degree program that, in general terms and in the social imaginary, does not offer a promising futures in terms of salaries, possibilities for promotion or incorporation into the corporate sector; in practice, being reduced to recruitment by the State (as educators or scientists). In addition, family influences in choosing a program, the existence of family members practicing as educators, vocational factors and their valuation of education as a tool for achievement and change, among many other factors, were analyzed. As such, histories were shared regarding life paths, sometimes intergenerational. Here we focus on the second technique used, the hierarchical evocation of words (Abric, 2001). In accordance with this technique, we asked individuals to mention terms they associated with each central Node. We later combine, by way of an procedure, the importance assigned to words and the frequency with which they were used and, in this way, we are able to discover which representations shared by groups and degree programs appear in the so-called "core" or "heart" of the representation (words that appear with high degrees of frequency and importance) and which are diversified in the three peripheral groups, each one more secondary. This allowed us to deepen our understanding of expectations, levels of satisfaction achieved with existing professional mobility, concerns and of the sense of wellbeing and achievement, among other dimensions analyzed.

\section{Results}

We will focus on some findings related to the central variables/dimensions.

In terms of Professional Status, the scientific system absorbs a very low percentage of PhDs: in Argentina, only five individuals entered this system, while the rest entered the academic system. In 
France, none entered the CNRS, as all were absorbed by the institution itself in positions such as ATER, "Vacataire" Professor, Academic Engineer and others.

As regards Mobility/Promotion, the "plafond" effect and the "line waiting theory" are observed to be much more marked for the French group. For the Argentine group, $70 \%$ of those who entered the doctoral program, even before finishing, experienced vertical mobility within the academic system (this finding also emerges in the quantitative stage of our research, at the correlational level) (Aparicio, 2009d).

Professional Satisfaction is, in general, high for both groups although the Argentine group holds higher expectations. Besides the fact that professional mobility is a given (though it does not greatly impact salaries), one of the central themes of the Argentine imaginary seems to endure. As Argentina is a relatively new country of European immigrants, its physiognomy is made up, in good part, by the dream of our predecessors: that their children and grandchildren would reach University. The Italians translate this into the phrase "my son, the doctor". And the country's open policy of accepting immigrants provided cultural incorporation, which was facilitated by an open, free and high quality University. Today, structural conditions have changed greatly; nevertheless, the "ideal" endures and higher levels of education continue to be seen as possible channels for upward social mobility. On the contrary, this idea never appears for the French group: workplace offerings do not favor those who opted for a degree in Education, and only favor other degree programs such as Management and Administration. Here, other values are given priority: particularly, economic benefit over vocation and management competencies must constantly struggle in the face of competition, which demands an education in other collective competencies not as necessary in the field of education.

This relative Satisfaction, despite some complaints, is explained in light of the Expectancy-Value theory and of the aspects which are valued and prioritized when choosing the field of Education; knowing that the professional field will be restricted (generally, to State positions) and that salaries will be relatively low (compared with other careers). However, this was the academic program chosen based on other values and, fundamentally, based on in a world in which competition leads to instability and even to suicide (as is the case for students from South Korea, who are subject to societal and family pressures in addition to pressures from the education system itself which demands professional achievement). For this reason, non-conformism does not dominate in our case. We observe that

. Results along this line were confirmed by a study carried out with Argentine researchers and which constituted the first replication of the principal studied in science and global conditioning factors of production (including organizational and psychosocial factors, always present in Aparicio's models) (Aparicio, 2014, Andrews, 1979). Here we can observe that for a stratified population of research team directors and key members who reach highlevel positions within the academic-scientific system, these individuals are the most dissatisfied as the demands that their level requires - both in terms of education in Administration and organizational competencies, and even for infrastructure and production support system (particularly subsidies) - are not accompanied by sufficient means. This is related to another theory, that of Anomie (applied here to professor-researchers). However, we must proceed. Aparicio's recent publications (USA, United Kingdom, India) refer to the conditioning factors of Satisfaction, to the point that she is able to coin the term "objective" satisfaction "subjective" satisfaction and "objective" mobility (horizontal or vertical changes in the hierarchical scale) "subjective" mobility (the feeling that this change in status was accompanied by a feeling a wellbeing).

In terms of education in abilities, that will later be competencies for daily action, demands for professionalization exist, although they fall under other labels. In Argentina, they are not systematized a national level and Professionalization is a term that is not widespread. This concept is known as "continuing education" or "permanent education" or "education throughout life". The frequency with which these terms emerge is high if we compare this group to the French group. This discrepancy between what the curriculum of higher education institutions should incorporate and what is currently demanded had already been established by studies of graduate students ( 20 cohorts, 18 degree 
programs at the UNCuyo and 17 cohorts of engineering at the UTN); the inattention paid to the cognitive-procedural dimension has also been clearly observed in PhD graduates and dropouts in Argentina (Cf. synthesis in Aparicio, 2005; 2007 a and b). In our case, the category emerging from words used by teachers - "cognitive-procedural" - appears empty for Argentine PhDs; on the other hand, it is located within the first periphery of social representations (also called elements of contrast) for the French group, portraying an important difference in the present day. This represents a call to attention for those responsible for management in our country, a call confirmed by our latest findings carried out with university professors (some of whom are PhDs). In contrast, "social" and "affective" competencies are much more widespread according to valuations provided by the PhDs themselves in Argentina, congruent with the country's idiosyncrasies.

Finally, our findings invite reflection. The institutional micro-system (such as the scientific system, system which absorbs PhDs), in addition to incongruencies between systems of "unsatisfied" expectations and preferences - which translate into valuations, options and decisions at the individual level while observing contextual offerings - produce ruptures of identity. At the same time, these condition functioning and behavior on other institutional, organizational and macro levels (not only national but also with impacts internationally). In other words, within the systemic interplay that has at its core, in our perspective, the "culture" (including values, norms, imaginaries, etc.), we observe a dialectic and spiral return that envelops both individuals and immediate and mediate contexts, with impacts on behaviors and experiences (positive and negative effects) which are not linear or determinist. These sometimes "unexpected" or unimagined impacts the result of education guided by traditional, Cartesian and rationalist logic -, must be kept in mind by those who manage education and employment programs if they are to introduce innovative reforms that respond to authentic needs and recover the authentic "reasons" that motivate our actions, beyond what is sustained by the media. Shall we return to the individual?

\section{Conclusions}

Contrasting profiles emerging from two doctorate programs of education in different contexts has allowed us to better observe how individual factors (sociocultural and psychosocial) interact with institutional factors and educational offerings in national contexts that have some historicalinstitutional aspects in common, but with different needs in today's world, and that are also positioned differently within a context of globalization that imposes conditions and restrictions. The criteria of "belonging" or response of institutions to contextual needs - one of the criteria for institutional quality - must be recovered in light of emerging research findings; an aspect sometimes dissociated from the political leanings in force and from practices themselves.

This could lead to reconsidering institutional lines: the saturation of doctoral degrees has a material and human cost for the State, in terms of frustration, non-conformism, fatalism and unfulfilled expectations, all of which will, in turn, return to the global system with negative effects. New market conditions demand a renewal of institutional identify if we wish to safeguard employability, health and human development, as well as the "relational" identity of individuals, today fragile in contexts where it is not easy to find recognition nor possibilities for promotion.

Finally, we must avoid extrapolation of findings and "blind" acceptance of that which is sustained in the literature produced in other contexts or in the media. As such, the devaluation of diplomas is not the same in both contexts, due to historical and structural factors: the "plafond" effect is felt very differently at the level of achievement, wellbeing and future expectations. The reality is more positive in Argentina because the closing of many doctorate programs during the military government impacted, in the medium term, the almost non-existent saturation of PhDs and, currently, underlies more positive expectations for the workplace in the future, with greater relative professional mobility being registered. We find ourselves facing a "perverse" effect of this positive impact in the present day. 
Teresita, M. A. (2017). PhD Graduates and Students: What professional pathways exist?.

[Online]. 4(1), pp 472-480. Available from: www.prosoc.eu

\section{References}

Abric, J. (2001).

Mexico: Ed. Coyoacan.

Andrews, F. M. \& Aichholzer, G. (1979).

Cambridge: Cambridge University Press.

Aparicio, M. (2003)

. Mendoza: ZETA.

Aparicio, M. (2004).

(59-63).Paris: L'Harmattan.

. In A. Lancry \& C. Lemoine,

Aparicio, M. (2008).

. San Juan: Edit. UNSJ.

Aparicio, M. (2009a)

UNCuyo:

EDIUNC.

Aparicio, M. (2009b).

UNCuyo:

EDIUNC.

Aparicio, M. (2009a).

3: ANRT.

Aparicio, M. (2009b).

Award. Marie de Paris, France.

Aparicio, M. (2014). Satisfaction, professional mobility and leadership in academic-scientific organizations. , 2(3), 135-145.

Aparicio, M. \& Cros, F. (2015a).

? Paris: L'Harmattan.

Aparicio, M. (2015). Identity, Weakening and Professionalization: A Study of Graduate and Postgraduate Students (1987-2002) in the Light of the Three-Dimensional Spiral of Sense Theory.

121-156.

Aparicio, M. (2015c). Towards a systemic theory: The three-dimensional spiral of sense. A study in Argentina Applied to Identity and Professionalization (Article 1).

2(7), 246-282.

Aparicio, M. (2015d). The theory of the three-dimensional spiral of sense: An application with special reference to identity and professionalization in other disciplinary areas. (Article 2).

2(7), 194-245.

Aparicio, M. (2016).

Dusseldorf, Germany.

Argyris, C. \& Schon, D. (1996).

Editions Universitaires Europeennes. OmniScriptum GmbH \& Co.KG.,

Harvard University/Cambridge.

Becker, G. (1964). . New York: National Bureau of Economic Research.

Boudon, R. (2001). Les causes de l'inegalite des chances scolaires. In: R. Boudon, N. Bulle \& M. Cherkaoui (eds.)

. Paris: PUF.

Bourdoncle, R. (1993). La professionnalisation des enseignants: Les limites d'un mythe.

83-119.

Dubar, C. (1991). Formation continue et dynamique des identites professionnelles.

87100.

Dubar, C. (1992).

Etzioni, A. (1969).

. Paris: La Documentation francaise.

Feather, N. \& Davenport, P. (1981). Unemployment and depressive effect: A motivational and attributional analysis.

(3), 422-436.

García Rodríguez, Y. (1993).

. Valencia: Promolibro.

Gelin, D., Rayou P. \& Ria, L. (2007).

Goffman, E. (1963).

. Paris: Armand Colin.

Heintz, P. (1970).

. Paris: Minuit.

Aires: Instituto.

Levy-Leboyer, C. (1971).

. Paris: PUF. 
Teresita, M. A. (2017). PhD Graduates and Students: What professional pathways exist?.

[Online]. 4(1), pp 472-480. Available from: www.prosoc.eu

Mingat A. \& Rasera, J. 1981.

. Dijon, University de Dijon: IREDU.

Ozga, J. \& Lawn, M. (1981)

. London: Palmer Press.

Tardif, M. \& Lessard, C. (1999).

, Bruxelles-Paris : De Boeck Universite.

Salanova, M., Martínez, I., Breso, E., Llorens, S. \& Grau, R., 2005. Bienestar psicologico en estudiantes universitarios: facilitadores y obstaculizadores del desempeno academic.

Silva, A.M. \& Aparicio, M. (Eds.) (2015).

, 21, 170-180.

. USA: Publishing 